\title{
Artificial Aging of Zirconium Dioxide: An Evaluation of Current Knowledge and Clinical Relevance
}

\author{
Özcan, Mutlu ; Volpato, Cláudia Ângela Maziero ; Fredel, Márcio Celso
}

DOI: https://doi.org/10.1007/s40496-016-0096-9

Posted at the Zurich Open Repository and Archive, University of Zurich ZORA URL: https://doi.org/10.5167/uzh-128020

Journal Article

Accepted Version

Originally published at:

Ȯzcan, Mutlu; Volpato, Cláudia Ângela Maziero; Fredel, Márcio Celso (2016). Artificial Aging of Zirconium Dioxide: An Evaluation of Current Knowledge and Clinical Relevance. Current Oral Health Reports, 3(3):193197.

DOI: https://doi.org/10.1007/s40496-016-0096-9 


\title{
Artificial Aging of Zirconium Dioxide: An Evaluation of Current Knowledge and Clinical Relevance
}

\author{
Mutlu Özcan ${ }^{1} \bullet$ Cláudia Ângela Maziero Volpato ${ }^{2} \bullet$ Márcio Celso Fredel $^{3}$
}

${ }^{1}$ University of Zurich, Dental Materials Unit, Center for Dental and Oral Medicine, Clinic for Fixed and Removable Prosthodontics and Dental Materials Science, Zurich, Switzerland

${ }^{2}$ Federal University of Santa Catarina, Health Sciences Center, Department of Dentistry, Florianópolis, Santa Catarina, Brazil

${ }^{3}$ Federal University of Santa Catarina, Technological Center, Department of Mechanical Engineering, Florianópolis, Santa Catarina, Brazil

M. Özcan*

University of Zurich, Dental Materials Unit, Center for Dental and Oral Medicine, Clinic for Fixed and Removablt Prosthodontics and Dental Materials Science, Plattenstrasse 11, CH-8032, Zurich, Switzerland e-mail: mutluozcan@hotmail.com 
Abstract Due to its superior mechanical properties, yttrium-stabilized tetragonal zirconia polycrystal is considered as one of the most promising materials to manufacture prosthetic frameworks, monolithic crowns and abutments for implants in dentistry. When stabilized in the tetragonal phase, the structure of zirconia car respond to external stress by increasing its toughness and resistance. Unfortunately, when subjected to humic environment, zirconia may undergo considerable degradation characterized by increased surface roughness grain growth and propagation of microcracks that could be detrimental for its mechanical properties. This phenomenon, also known as low-temperature degradation (LTD), when not minimized, may represent : setback for the longevity of zirconia especially used for biomedical applications. LTD is studied in in vitro or it vivo settings employing different strategies. Present clinical studies however, with their shortcomings, do no signify high incidence of failures of zirconia for dental applications. The LTD of zirconia is currently beins criticized based on laboratory testing which may be suboptimal. This review will highlight the existins knowledge on the artificial aging methods studying LTD in zirconia and their relevance considering clinica performance of zirconia prostheses.

Keywords Aging $\bullet$ Low temperature degradation $\bullet$ Zirconia $\bullet$ Y-TZP 


\section{Introduction}

With the introduction of CAD/CAM technologies, many dental reconstructions, which could be rehabilitatec with metal-ceramic, can currently be restored with ceramic materials [1,2]. Among all other ceramic alternatives, Yttrium-stabilized tetragonal zirconia polycrystal (hereon: zirconia) has more potential for divers dental applications. Due to its biocompatibility, superior mechanical properties, chemical stability anc laboratory versatility, zirconia has been indicated to manufacture monolithic crowns, frameworks of fixed denta prostheses (FDPs), root posts, implant abutments and implants [3-5].

\section{Zirconia as a biomaterial}

Zirconia is a white oxide that displays a singular allotropic effect. With the same composition, it can presen three different crystal structures transforming as a function of temperature, namely monoclinic (from roon temperature up to $\left.1170^{\circ} \mathrm{C}\right)$, tetragonal $\left(1170-2370^{\circ} \mathrm{C}\right)$ and cubic phase $\left(>2370^{\circ} \mathrm{C}\right)$ [6]. Among all three phases the monoclinic phase is mechanically the weakest and predominates pure zirconia. It is essential to maintair zirconia in the tetragonal and/or cubic phase at room temperature in order to benefit from its mechanica properties [7]. For this purpose, typically oxides $(\mathrm{CaO}, \mathrm{MgO})$ and rare earths $\left(\mathrm{CeO}_{2}, \mathrm{Y}_{2} \mathrm{O}_{3}\right)$ are added tc zirconia, stabilizing this material fully or partially at these phases [8]. According to the ISO 13356, yttrium oxide $\left(\mathrm{Y}_{2} \mathrm{O}_{3}\right)$ is the most suitable stabilizer for medical use [9] where usually about 3 to 6 mol\% of $\mathrm{Y}_{2} \mathrm{O}_{3}$ is capable o stabilizing zirconia in the tetragonal phase [10].

Zirconia is considered as a structural material due to the fact that when subjected to stress, it can change its microstructure, improving its mechanical performance [8]. In general, ceramic materials do not exhibi deformation capability and when submitted to stresses, fractures may occur as a result of crack propagatior originating from internal or external defects. However, when a crack propagates into zirconia structure tetragonal metastable crystals close to the crack tip transforms spontaneously into the monoclinic phase ( $t \rightarrow n$ 
phase transformation) resulting in a volumetric expansion of about 3 to $5 \%$ [11]. This volume increase induces compressive stresses that oppose the growth and propagation of the crack, resulting in a mechanism knowr as "transformation toughening" $[12,13]$. During this process, the crystalline structure of the material changes Hence, without mass transfer, simultaneous movement of the atoms results in modification of the macroscopic shape of the processed areas that considerably improves the strength of zirconia [13].

Since the energy available for crack propagation is in part dissipated in the damaged area shaped by the monoclinic zirconia, transformation toughening occurs [14]. However, when the increase in volume exceeds the elastic limit of zirconia, it can promote the crack propagation, inducing new microcracks and ever catastrophic fracture of the structure [8]. This mechanism could be influenced by several factors that act in ar isolated form or associated, such as shape, size and location of grains, presence of defects and/or oxyger vacancies in the structure, type and amount of stabilizing oxides, manufacturing methods, applied stresses and temperature variation [3].

More recently, with the introduction of CAD/CAM technologies and aesthetic requirements, zirconia was introduced in dentistry. Commercial blocks, obtained through isostatic compaction of zirconia nanoparticles (20-30 nm) could be machined by CAD/CAM milling technologies and sintered at high temperature furnaces [3]. The microstructure of zirconia at this stage is mainly composed of tetragonal grains.

\section{Low-temperature degradation}

Zirconia is a chemically inert material with low toxicity $[3,15]$. Owing to its high flexural, fracture strength hardness, modulus of elasticity and wear resistance [4], in the late 80 s, zirconia has been used in medicine tc manufacture orthopedic femoral head prostheses [14-16]. Unfortunately, between 2000 and 2002, a largt number of failures were observed in a short period of time, generating a major public health concern. Thes 
failures have drawn attention of the scientific community and consequently, efforts have been made in order tc search for the origin of such premature failures of orthopedic prostheses experienced.

Several researchers observed that zirconia is destabilized in the presence of water or water vapour and the moisture favoured the $t \rightarrow m$, significantly increasing the monoclinic content and ultimately, the surfact roughness of the material $[16,17]$. The phenomenon responsible for such premature failures was ther attributed to hydrothermal degradation or low-temperature degradation (LTD), known as aging of zirconia ir the medical field $[17,18]$. Subsequent studies also supported the hypothesis that when zirconia is exposed tc humid environment, aging can take place at varying degrees $[14,15,18]$.

LTD is a structural degradation phenomenon that starts on the zirconia surface and continues when it is ir contact with water or water vapour at moderate temperatures ranging between 150 and $400^{\circ} \mathrm{C}$ [19]. Tht presence of moisture interferes with the metastability of its microstructure, and makes the material susceptible to aging $[6,15,18,20]$. Usually, the surface transformation is slow, spontaneous and progressive. LTD starts with the stress corrosion mechanism where the diffusion of water into the zirconia grains occurs through fillins the oxygen vacancies and causes stresses in the crystalline network, which then disorganizes the structure o the material [6]. This scenario is characterized by nucleation and growth of the transformed grains, successive grain pull-out and micro or macrocracks formation, also known as subcritical crack growth (SCG) phenomenor [17]. As the grain size increases with the increase in monoclinic phase, the result is the formation of a patt created by cracks through which water penetrates, further increasing the susceptibility to LTD [6].

Several theories have been proposed in order to elucidate the LTD [21-23]. Early theories postulated tha LTD occurs due to chemisorption of water molecules $[21,24]$ that could break the Y-O bonds, which is alsc known as SCG. The classic model proposed by Guo [25] described the LTD phenomena in sequential phases a) water chemical adsorption on the grain surface; b) water reaction with oxygen, forming hydroxyl groups; c penetration of the hydroxyl groups into the mass by diffusion around the grain; d) formation of proton defects 
by filling the oxygen vacancies with hydroxyl ions; and e) $t \rightarrow m$ transformation reducing the concentration 0 oxygen vacancies. On the other hand, the most widely accepted theory suggests that the increase in interna stresses associated with the penetration of water triggers the $t \rightarrow m$ phase transformation, yielding to LTD [26].

In fact, aging of zirconia is the result of the influence of multiple factors. The $t \rightarrow m$ transformation is strongl! induced by the presence of water or water vapor [25], material susceptibility [20], shape, size and grair location and stabilizer content [27]. In this regard, after aging, depending on the composition, zirconia shows variability in the mechanical behaviour due to different levels of $t \rightarrow m$ transformation zones $[28,29]$. Th

reduction in the resistance of zirconia appears to be closely linked to a more pronounced depth in the transformation zones $[30,31]$. However, the shape, size and location of the grains appear to have the highes impact on phase transformation in that larger grains are more easily transformed than smaller ones $[10,22,27]$ Parameters such as aging duration, temperature and pressure also determine the intensity of transformation Aging duration longer than $20 \mathrm{~h}$, pressure of 2 bar and temperature of $134^{\circ} \mathrm{C}$ seems to be the ideal parameters in order to promote LTD in zirconia specimens $[20,23]$. Experimental studies also demonstrated grain growtr with the increase in temperature [3,32] and that the resulting degradation is dependent on the duration 0 exposure to the heat [33]. However, recently $t \rightarrow m$ phase transformation was also reported even at ora temperatures [34].

\section{Methods for LTD simulation}

To date there is little in vivo data on the effect of LTD on zirconia. In 1993, Shimizu et al. evaluated aging o zirconia specimens that were placed in the subcutaneous tissue of rabbits, stored in saline solution at $37,5($ and $95^{\circ} \mathrm{C}$ for 36 months or by aging them in autoclave at $121^{\circ} \mathrm{C}$ for $960 \mathrm{~h}$ [35]. The results indicated simila levels of aging in in vivo and in vitro conditions. Thus, the authors suggested that in vitro studies could be usec to screen hydrothermal degradation of zirconia. Recently, in an in vivo model, LTD was studied after placins 
zirconia discs with two different grain sizes $(0.32$ and $0.44 \mu \mathrm{m})$ in removable mandibular dentures [36]. After 6 12 and 24 months exposure to the oral cavity, discs were removed from the prostheses and the surfaces wert analyzed using X-ray Diffraction (XRD) and Field Emission Gun Scanning Electron Microscope (FEG-SEM) The results showed that regardless of the grain size, zirconia specimens were vulnerable to $t \rightarrow m$ phase transformation due to chemical changes in the aggressive oral environment [36].

In a series of classical in vitro studies, Chevalier et al. evaluated the LTD of zirconia in an autoclave at $134^{\circ} \mathrm{C}$ for $1 \mathrm{~h}$, representing an equivalent to 3 to 4 years of in vivo aging $[14,23,37]$. On the other hand, Internationa Organization of Standardization (ISO 13356:2015) recommends employing autoclave aging at $134^{\circ} \mathrm{C}$ unde 0.2 MPa pressure for $5 \mathrm{~h}$ as an accelerated aging protocol for zirconia [9]. As an alternative to autoclave aging other laboratory tests have been also used to predict and to elucidate the LTD in zirconia such as thermocycling [28,30], mechanical cycling [30], storage in water [37], saliva [31], saline solution $[38,39]$ anc acetic acid $[39,40]$.

For the accelerated aging protocol in autoclave, the temperature employed in most studies is $134^{\circ} \mathrm{C}$ $[9,23,28,29,32,41,42]$ which is also the recommendation of ISO 13356:2015 [9]. However, the duration o exposure of the specimens vary between $1 \mathrm{~h}$ to $960 \mathrm{~h}[32,41,42]$ where $t \rightarrow m$ phase transformation is directl! proportional to the duration of aging $[31,32,42]$. Unfortunately, the lack of standardization for the LTD methor considering duration, temperature, storage in various chemicals makes it difficult to compare LTL phenomenon and suggest strategies to minimize its development [20].

\section{Clinical relevancy}

The validity of the accelerated aging protocols and their relevance to the longevity of the zirconic reconstructions remains a question in clinical dentistry $[6,20]$. Since accelerated aging of zirconia is investigated at higher temperatures than the human body, the testing environment could not be considerec 
representative for the oral environment, and that the extrapolation of in vitro findings should be made witl caution [20].

Although clinical follow-up studies of anterior FDPs with zirconia frameworks showed a success rate of $88.8 \%$ up to 7 years [43], there is still concern on the possible consequences of LTD in zirconia materials used fo dental applications. Especially abutments, FDP frameworks without veneering ceramic or monolithic crowns are directly exposed to the oral environment [44]. Moreover, it has to be noted that already durins manufacturing, as a result of CAD/CAM milling along with clinical and laboratory procedures, abutments crowns or FDPs made of zirconia are subjected to damage. Such damage undermines the initial favourable mechanical properties of zirconia [4] that can eventually compromise the longevity of such prostheses especially when they are in contact with the oral environment $[37,45]$.

Zirconia ceramics available for clinical use present dissimilarities but the hydrothermal transformatior mechanism could in fact be controlled or minimized during industrial, laboratory and clinical processing. Durins industrial processing, zirconia ceramic blocks could be produced with controlled density to prevent the destabilization of the tetragonal zirconia microstructure. In addition, alumina traces $\left(\mathrm{Al}_{2} \mathrm{O}_{3}\right)[38,46]$, silica and/o ceria $\left(\mathrm{CeO}_{2}\right)$ [39] could be added to the composition to improve the resistance of zirconia against LTD. Ir particular, ceria as an oxide demonstrates favourable stabilization effect as it has concentration of about 1 : mol\% and makes zirconia non-transformable $[47,48]$.

LTD could also be avoided during laboratory processing by ceramic infiltration and thermal control. In order tc shield the surface of zirconia and prevent its contact with humidity, the use of ceramic infiltration with glas: ceramic having thermal expansion coefficient similar to that of zirconia could be recommended $[49,50]$. As fo the temperature control, zirconia is typically sintered at temperatures between $1400^{\circ} \mathrm{C}$ and $1450^{\circ} \mathrm{C}$ [14] Temperatures exceeding $1550^{\circ} \mathrm{C}$ cause grain growth of up to $0.75 \mu \mathrm{m}$ that is above the recommendations o ISO 13356:2015 $(0.6 \mu \mathrm{m})$ [17]. The resulting grain growth increases the monoclinic content of zirconia anc 
thereby susceptibility to LTD $[32,33]$. Thus, it is essential to sinter zirconia at temperatures low enough in orde to avoid larger grain formation but high enough to generate dense structures ensuring cohesion between the zirconia grains. Lower density also facilitates the penetration of water to the bulk of the material, resulting ir formation of pores and crack surfaces, greatly increasing LTD. [24].

Clinical strategies involve factors that can be controlled by the dental professional such as the establishmen of an appropriate tooth preparation with sufficient depth, rounded interior angles and cervical finish lines Careful tooth preparation allows for more accurate image processing and CAD/CAM milling, and ensures fewer adjustments on the zirconia surface during clinical try-in [51]. Likewise, every time adjustments are madt on the zirconia surface, the damage caused by the burs or disks can deteriorate the surface integrity 0 zirconia [52]. Superficial roughness created on the material can then introduce defects and increase the susceptibility to $t \rightarrow m$ phase transformation [20]. Thus, repeated slow heating and cooling of the zirconic reconstruction after adjustments and veneering could dissipate the stresses created by burs or disks.

\section{Concluding remarks}

Current knowledge, implications and consequences of low-temperature degradation effect on zirconia arє mainly based on accelerated aging studies. Clinical follow-up studies should elucidate the in vivc consequences of this phenomenon, providing that current studies either lack the power or comprise man! confounding factors. At this stage, it is essential that the dental professionals should perform laboratory anc clinical procedures meticulously considering factors highlighted in this review in order to minimize the agins process, maintaining mechanical properties and increasing the longevity of zirconia prosthesis.

\section{Conflict of Interest}

The authors declare that they have no conflict of interest. 


\section{References}

Papers of particular interest, published recently, have been highlighted as:

- Of importance

•• Of major importance

1. Larsson C, Wennerberg A. The clinical success of zirconia-based crowns: a systematic review. Int . Prosthodont. 2014;27(1):33-43.

2. Ferrari M, Vichi A, Zarone F. Zirconia abutments and restorations: From laboratory to clinica investigations. Dent Mater. 2015;31(3):e63-e76.

3. Uo M, Sjögren G, Sundh A, et al. Cytotoxicity and bonding property of dental ceramics. Dent Mater 2003;19(6):487-92.

4. Denry I, Kelly JR. State of the art of zirconia for dental applications. Dent Mater. 2008;24(3):299-307.

5. Vagkopoulou T, Koutayas SO, Koidis P, et al. Zirconia in Dentistry: Part 1. Discovering the nature of ar upcoming bioceramic. Eur J Esthet Dent. 2009;4(2):130-51.

6. "Lughi $\mathrm{V}$, Sergo V. Low temperature degradation - aging - of zirconia: A critical review of the relevan aspects in dentistry. Dent Mater. 2010;26(8):807-20. This review article focuses on the effects of LTD or zirconia and the main implications for dental applications.

7. Guazzato M, Albakry M, Ringer SP, et al. Strength, fracture toughness and microstructure of a selection o all-ceramic materials. Part II. Zirconia-based dental ceramics. Dent Mater. 2004;20(5):449-56.

8. Kelly JR, Denry I. Stabilized zircônia as a structural ceramic: An overview. Dent Mater. 2008;24(3):289-98.

9. International Standards Organization: Implants for surgery - Ceramic materials based on yttria-stabilizec tetragonal zirconia (Y-TZP). No:13356:2008 - revised No:13356:2015.

10. Kumar BVM, Kim WS, Hong S, et al. Effect of grain size on wear behavior in Y-TZP ceramics. Mater Sc Eng A. 2010;527(3):474-9. 
11. Hannink RHJ, Kelly PM, Muddle BC. Transformation toughening in zirconia-containing ceramics. J An Ceram Soc. 2000;83(3):461-87.

12. Garvie RC, Hannonk RH, Pascoe RT. Ceramic steel? Nature. 1975;258:703-4.

13. Kelly PM, Francis Rose LR. The martensitic transformation in ceramics-its role in transformatior toughening. Prog Mater Sci. 2002;47(5):463-557.

14. Chevalier J, Deville S, Münch E, et al. Critical effect of cubic phase on aging in 3 mol\% yttria-stabilizec zirconia ceramics for hip replacement prosthesis. Biomaterials. 2004;25(24):5539-45.

15. Cales B, Stefani Y, Lilley E. Long-term in vivo and in vitro aging of a zirconia ceramic used in orthopaedy J Biomed Mater Res. 1994;28(5):619-24.

16. Piconi C, Burger W, Richter HG, et al. Y-TPZ for artificial joint replacements. Biomaterials 1998;19(16):1489-94.

17. Chevalier J. What future for zirconia as a biomaterial? Biomaterials. 2006;27(4):535-43.

18. Chevalier J, Gremillard L, Virkar AV, et al. The tetragonal-monoclinic transformation in zirconia: lessons learned and future trends. J Am Ceram Soc. 2009;92(9):1901-20.

19. Kobayashi $\mathrm{K}$, Kuwajima $\mathrm{H}$, Masaki T. Phase change and mechanical properties of $\mathrm{ZrO}_{2}-\mathrm{Y}_{2} \mathrm{O}_{3}$ solic electrolyte after aging. Sol Stat Ion. 1981;3/4:489-95.

20. **Pereira GK, Venturini AB, Silvestri T, et al. Low-temperature degradation of Y-TZP ceramics: c systematic review and meta-analysis. J Mech Behav Biomed. 2016;55:151-63. This is a meta-analyses or low-temperature degradation of zirconia in autoclave. The paper concludes that aging parameters suct as duration of aging, pressure and temperature affect mechanical properties and in particular the flexural strength.

21. Lange FF, Dunlop GL, Davis BI. Degradation during aging of transformation-toughed $\mathrm{ZrO}_{2}-\mathrm{Y}_{2} \mathrm{O}_{3}$ materials at $250^{\circ} \mathrm{C}$. J Am Ceram Soc. 1986;69(3):237-40. 
22. Sato $\mathrm{T}$, Shimada M. Transformation of yttria-dopped tetragonal $\mathrm{ZrO}_{2}$ polycrystais by annealing in water. , Am Ceram Soc. 1986;68(6):356-9.

23. ${ }^{* *}$ Chevalier L, Cales B, Drouet JM. Low temperature aging of Y-TPZ ceramics. J Am Ceram Soc 1999;82(8):2150-4. This classical article presents the aging protocol in autoclave at $134{ }^{\circ} \mathrm{C}$ for $1 \mathrm{~h}$ anc suggest this protocol equivalent to $3-4$ years of in vivo aging.

24. Yoshimura M, Noma T, Kawabata K, et al. Role of $\mathrm{H}_{2} \mathrm{O}$ on the degradation process of Y-TZP. J Mater Sc Lett. 1987;6(4):465-7.

25. Guo X. On the degradation of zirconia ceramics during low-temperature annealing in water or water vapor J Phy Chem Solids. 1999;60(4):539-46.

26. Schubert H, Frey F. Stability of Y-TZP during hydrothermal treatment: neutron experiments and stabilit! considerations. J Eur Ceram Soc. 2005;25(9):1597-602.

27. Luthardt RG, Holzhüter M, Sandkuhl O, et al. Reliability and properties of ground Y-TZP zirconia ceramics J Dent Res. 2002;81(7):487-91.

28. Flinn BD, deGroot DA, Mancl LA, et al. Accelerated aging characteristics of three yttria-stabilizec tetragonal zirconia polycrystalline dental materials. J Prosthet Dent. 2012;108(4):223-30.

29. Perdigão J, Pinto AM, Monteiro RC, et al. Degradation of dental $\mathrm{ZrO}_{2}$-based materials after hydrotherma fatigue. Part I: XRD, XRF, and FESEM analyses. Dent Mater J. 2012;31(2):256-65.

30. Borchers L, Stiesch M, Bach FW, et al. Influence of hydrothermal and mechanical conditions on the strength of zirconia. Acta Biomater. 2010;6(12):4547-52.

31. Alghazzawi TF, Lemons J, Lui PR, et al. Influence of low-temperature environmental exposure on the mechanical properties and structural stability of dental zirconia. J Prosthodont. 2012;21(5):363-9.

32. Denry IL, Peacock JJ, Holloway JA. Effect of heat treatment after accelerated aging on phast transformation in 3Y-TZP. J Biomed Mater Res B Appl Biomater. 2010;93(1):236-43. 
33. Cattani-Lorente M, Durual S, Amez-Droz M, et al. Hydrothermal degradation of a 3Y-TZP translucen dental ceramic: A comparison of numerical predictions with experimental data after 2 years of aging. Den Mater. 2016;32(3):394-402.

34. Keuper M, Berthold C, Nickel KG. Long-time aging in 3 mol.\% yttria-stabilized tetragonal zirconic polycrystals at human body temperature. Acta Biomater. 2014;10(2):951-9.

35. *Shimizu K, Oka M, Kumar P, et al. Time-dependent changes in the mechanical properties of zirconic ceramic. J Biomed Mat Res. 1993;27(6):729-34. ${ }^{*}$ This is the first study on LTD effect on zirconia ir animals.

36. *Kosmac T, Jevnikar P, Kocjan A. In vivo ageing of dental zirconia ceramics: 24-months results. Den Mater. 2011;27S:e60-1. *This is the first in vivo study on LDT of zirconia.

37. Deville S, Chevalier J, Gremillard L. Influence of surface finish and residual stresses on the ageins sensitivity of biomedical grade zirconia. Biomater. 2006;27(10):2186-92.

38. Papanagiotou HP, Morgano SM, Giordano RA, et al. In vitro evaluation of low-temperature aging effects and finishing procedures on the flexural strength and structural stability of Y-TZP dental ceramics. J Prosthe Dent. 2006;96(3):154-64.

39. Ban S, Sato H, Suehiro $\mathrm{Y}$, et al. Biaxial flexure strength and low temperature degradation of $\mathrm{Ce}-\mathrm{TZP} / \mathrm{Al}_{2} \mathrm{O}$ nanocomposite and Y-TZP as dental restoratives. J Biomed Mater Res B Appl Biomater 2008;87(2):492-8. 40. Ardlin BI. Transformation-toughened zirconia for dental inlays, crowns and bridges: chemical stability anc effect of low-temperature aging on flexural strength and surface structure. Dent Mater. 2002;18(8):590-5.

41. Hallmann L, Mehl A, Ulmer $P$, et al. The influence of grain size on low-temperature degradation of denta zirconia. J Biomed Mater Res Part B Appl Biomater 2012;100(2):447-456.

42. Kohorst P, Borchers L, Strempel J, et al. Low-temperature degradation of different zirconia ceramics fo dental applications. Acta Biomater 2012; 8(3):1213-20. 
43. Ozer F, Mante FK, Chiche G, et al. A retrospective survey on long-term survival of posterior zirconia anc porcelain-fused-to-metal crowns in private practice. Quintessence Int. 2014;45(1):31-8.

44. Cattani-Lorente M, Scherrer SS, Ammann $\mathrm{P}$, et al. Low temperature degradation of a Y-TZP denta ceramic. Acta Biomater. 2011;7(2):858-65.

45. Kosmac T, Dakskobler A, Oblak C, et al. The strength and hydrothermal stability of Y-TZP ceramics fo dental applications. Int J Appl Ceram Technol. 2007;4(2):164-74.

46. Tanaka K, Tamura J, Kawanabe K, et al. Phase stability after aging and its influence on pin-on-disk wea properties of Ce-TZP/Al ${ }_{2} \mathrm{O}_{3}$ nanocomposite and conventional Y-TZP. J Biomed Mater Res A. 2003;67(1):200 7.

47. Tsukuma K. Mechanical properties and thermal stability of $\mathrm{CeO}_{2}$ containing tetragonal zirconia poly crystals. Am Ceram Soc Bull. 1986;65(10):1386-89.

48. Camposilvan E, Flamanta Q, Anglada M. Surface roughned zirconia: towards hydrothermal stability. . Mech Behav Biomed. 2015;47:95-106.

49. Zhang Y, Kim JW. Graded structures for damage resistant and aesthetic all-ceramic restorations. Den Mater. 2009;25(6):781-90.

50. Zhang Y, Chai H, Lawn BR. Graded structures for all-ceramic restorations. J Dent Res 2010;89(4):417-21. 51. Garbelotto LGD, Maziero Volpato CA, Rocha M, et al. Laboratory and clinical considerations on prosthetic zirconia infrastructures for implants. Implant Dent. 2013;22(6):578-83.

52. Al-Haj Husain N, Özcan M. A study on topographical properties and surface wettability of monolithic zirconia after use of diverse polishing instruments with different surface coatings. J. Prosthodont. 2016 (Epub) 